\title{
Vertical distribution and sedimentation of volatile phenols in Jiaozhou
} Bay

\author{
Dongfang Yang ${ }^{1,2, a}$, Xinhuai $\mathrm{He}^{1}$, Jie Gao ${ }^{1}$, Ping Wang ${ }^{1}$ and Feijuan Wang ${ }^{1}$
}

${ }^{1}$ College of medicine, Shaanxi institute of international trade \& commerce, Xian 712046, China;

${ }^{2}$ North China Sea Environmental Monitoring Center, SOA, Qingdao 266033, China

adfyang_dfyang@126.com

Keywords: Volatile phenols, Vertical distribution, Seasonal variation, Transfer process, Jiaozhou Bay.

\begin{abstract}
This paper analyzed the vertical distribution and sedimentation of volatile phenols in bottom waters in Jiaozhou Bay in 1982. Results showed that the pollution level of volatile phenols in bottom waters in Jiaozhou Bay was very low in 1982, which were increasing from spring, and then reaching the peak in summer, and finally decreasing from autumn. Sedimentation was one of the major transfer processes in volatile phenols in Jiaozhou Bay, which was determining the distributions of volatile phenols in waters.
\end{abstract}

\section{Introduction}

Volatile phenols were one class of the critical industrial pollutants [1]. More and more volatile phenols were discharged to the environment in the past 30 years in China. Ocean is the sink of pollutants. Volatile phenols could be inputted to the ocean by atmospheric deposition, rainfall-runoff, waste water discharge etc., and the volatile phenols pollution in the ocean could be a risk to the ecosystem, and finally cause harms to human. Therefore, the research of volatile phenols pollution in ocean is essential to environmental protection.

Jiaozhou Bay is located in Shandong province, which had been rapidly developing after reform and opening-up. In order provided background information for environmental protection and remediation of volatile phenols in Jiaozhou Bay, this paper analyzed the vertical distribution and seasonal variation of volatile phenols in Jiaozhou Bay in 1982.

\section{Material and method}

Jiaozhou Bay $\left(35^{\circ} 55^{\prime}-36^{\circ} 18^{\prime} \mathrm{N}, 120^{\circ} 04^{\prime}-120^{\circ} 23^{\prime} \mathrm{E}\right)$ is located in the south of Shandong Province, eastern China. It could be seen from Fig. 1 that this bay is a semi-closed bay, with some inflow rivers; most of which have seasonal features [2].

The data in this research was provided by North China Sea Environmental Monitoring Center. The survey was conducted in April, July and October 1982. Five monitoring sites (083, 084, 121, 122 and 123) were setup in the southwest of the bay. 


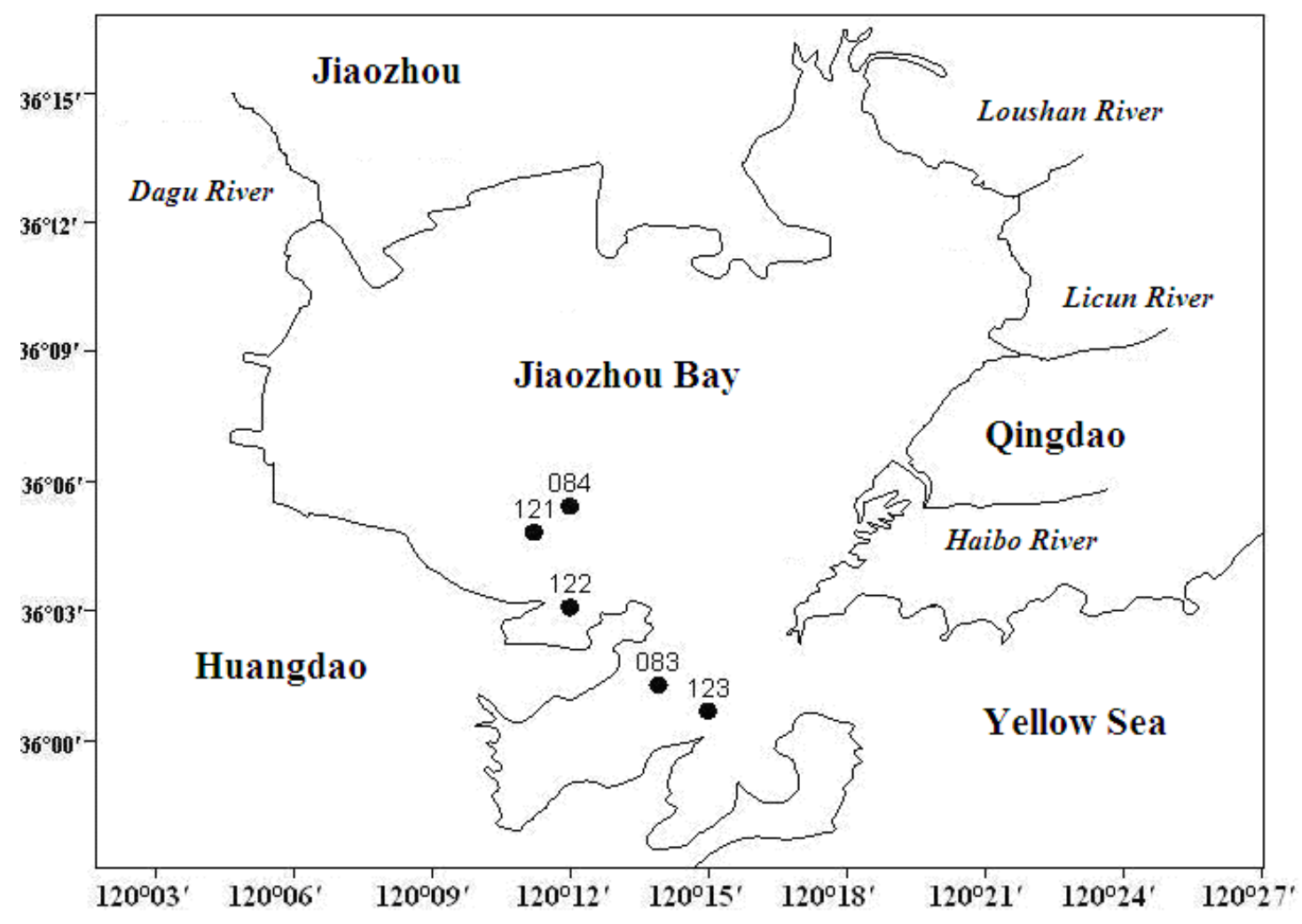

Fig.1 Geographic location and monitoring sites in Jiaozhou Bay

\section{Results and discussion}

Contents and distributions of volatile phenols. The contents of volatile phenols in bottom waters in April, July and October ranged from 1.65-2.02 $\mu \mathrm{g} . \mathrm{L}^{-1}, 1.12-3.08 \mu \mathrm{g} . \mathrm{L}^{-1}$ and $0.45-2.80$ $\mu \mathrm{g} . \mathrm{L}^{-1}$, respectively (Fig. 2a-c). In comparison with Grade I $\left(5.00 \mu \mathrm{g} . \mathrm{L}^{-1}\right)$ for volatile phenols in National Sea Water Quality Standard (GB 3097-1997), the pollution level of volatile phenols in Jiaozhou Bay was very low in 1982. The volatile phenols contents in bottom waters were increasing from spring, and then reaching the peak in summer, and finally decreasing from autumn. The spatial distributions of volatile phenols contents in bottom waters in different seasons were showing similar trends, which were decreasing the bay mouth in the southwest to the center of the bay. From spring, the amount of precipitation was increasing and reaching the peak in summer, so do the contents of volatile phenols in the bay. However, the amount of precipitation was decreasing in autumn, and the contents of volatile phenols were also decreasing. 


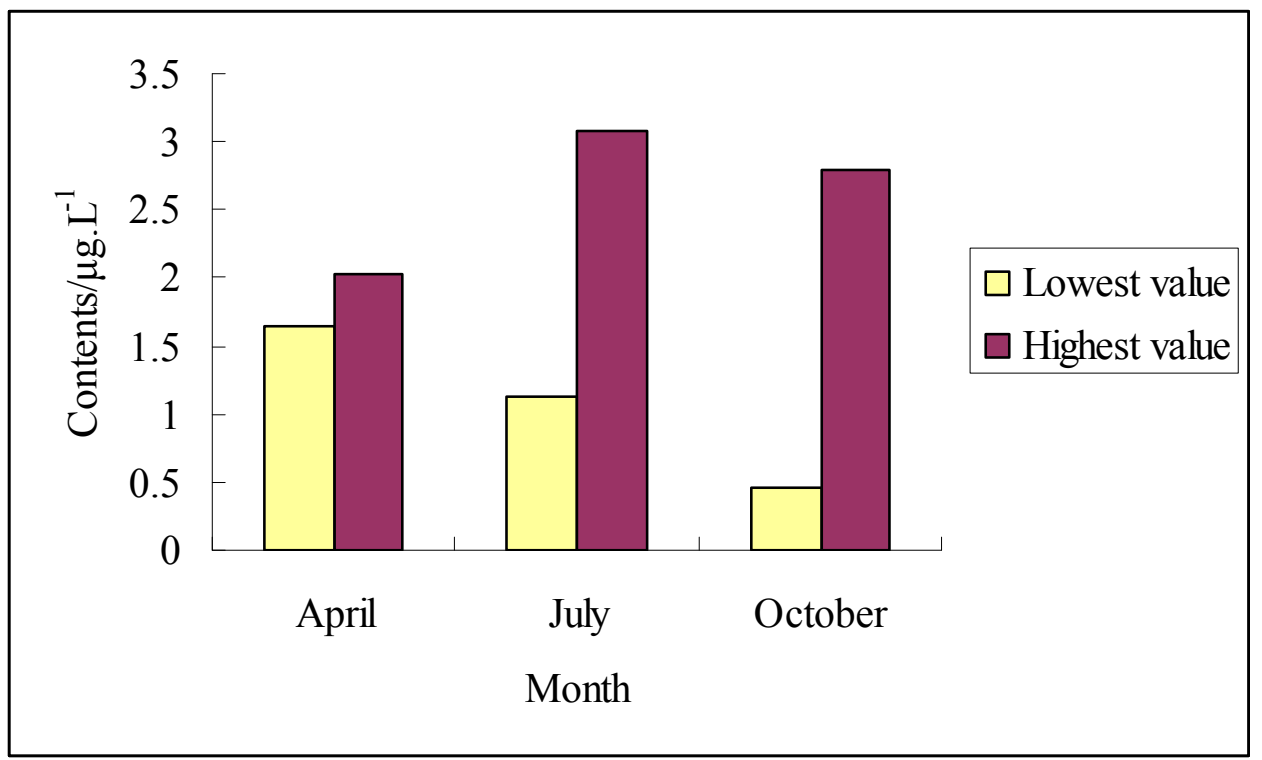

Fig.2 Volatile phenols contents in bottom waters in April, July and October 1982 in Jiaozhou

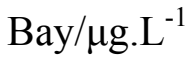
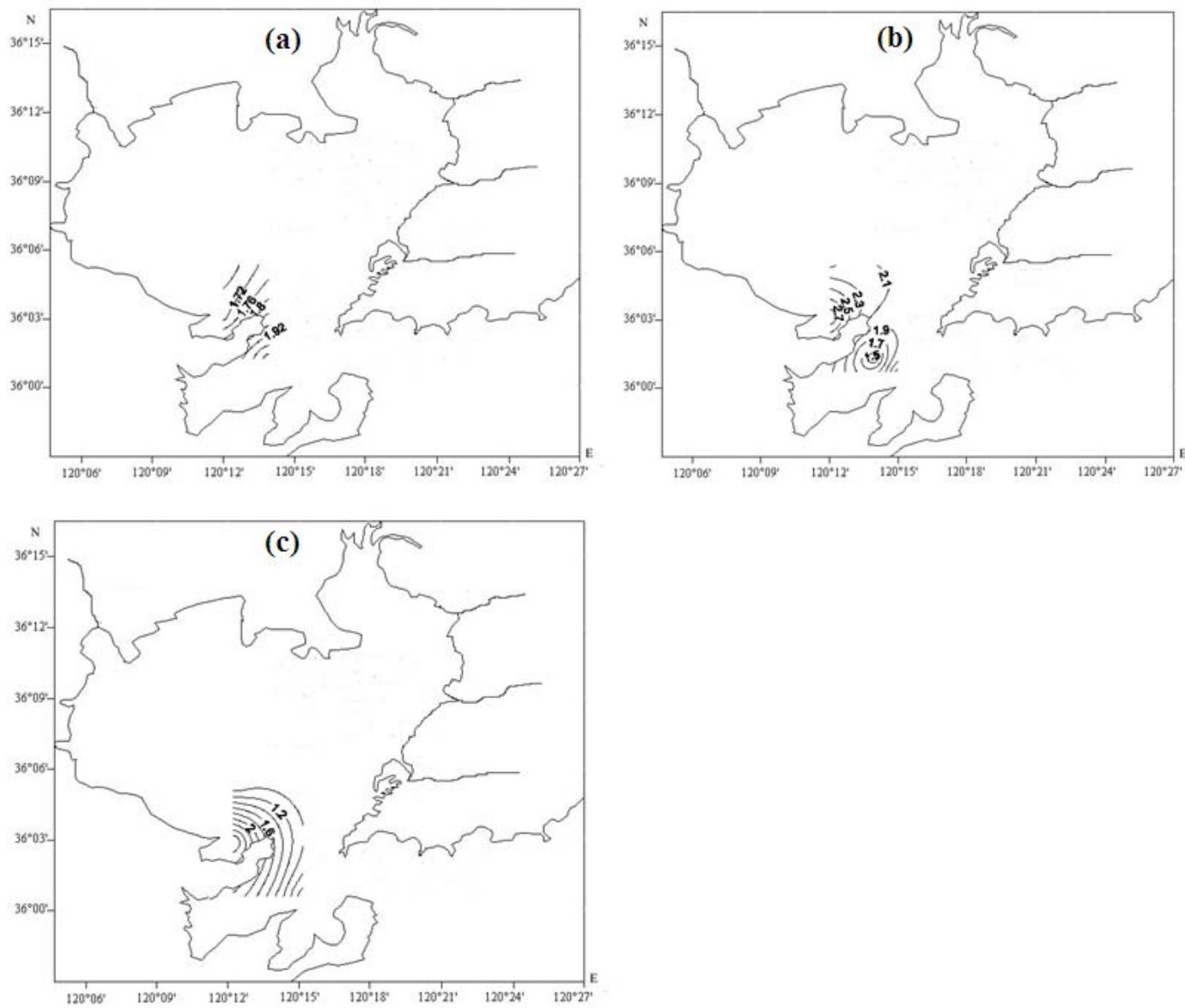

Fig.2 Distributions of volatile phenols in a) April, b) July and c) October 1982 in bottom waters in

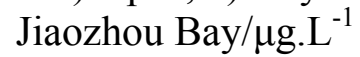

Sedimentation of volatile phenols. Volatile phenols were low molecular weight and strong hydrophilic, which could be strongly absorbed to the phytoplankton and suspended particulate matters in the ocean. In spring, the growth and reproduction of marine organism is beginning to increase, and then is reaching the climax in summer [3]. In spring and summer, a lot of volatile phenols were inputted to the bay from the rivers, and a large amount of volatile phenols could be absorbed to the suspended particles, and therefore the vertical sedimentation of volatile phenols was 
increasing. The amount of precipitation was decreasing in autumn, and the inputs of volatile phenols were limited, as well as the sedimentation of phenols was decreasing, leading to the decreasing of volatile phenols contents in waters be means of sedimentation and water exchange. Above all, it could be concluded that the distributions of volatile phenols were mainly determined by vertical sedimentation process in Jiaozhou Bay.

\section{Conclusion}

The pollution level of volatile phenols in bottom waters in Jiaozhou Bay was very low in 1982, which were increasing from spring, and then reaching the peak in summer, and finally decreasing from autumn. Sedimentation was one of the major transfer processes in volatile phenols in Jiaozhou Bay, which was determining the distributions of volatile phenols in waters.

\section{Acknowledgement}

This paper was sponsored by Education Ministry's New Century Excellent Talents Supporting Plan (NCET-12-0659), Project of Outstanding Technological Educators of Governor of Guizhou ([2012]71), Project of Low Carbon Technology Plan of Guiyang (2012205]), Project of Science and Technology Foundation of Guiyang (LKM[2012]05), Special Research Projects of High Level Talents of Guizhou Province (TZJF-2011-44), and Research Projects of Guizhou Nationalities University ([2014]02).

\section{References}

[1] Hongxia Liu and Qiong Li: Environ. Sci. Manag., Vol. 37 (2002) , p. 132-137. (in Chinese)

[2] Dongfang Yang, Yu Chen, Zhenhui Gao, Jing Zhang and Fan Wang: Chin. J. OceanoL. LimnoL., Vol. 23(2005), p. 72-90.

[3] Dongfang Yang, Fan Wang, Zhenhui Gao, Wenlin Cui and Suxia Huo: Mar. Sci., Vol. 28(2004), p.71-74.(in Chinese) 